\title{
William Klemperer
}

\author{
Innovative and versatile, William Klemperer devised both unorthodox experimental tools that enhanced molecular \\ spectroscopy and a theoretical model that elucidated the paradoxical chemistry of cold interstellar clouds.
}

$\mathrm{B}$ ill Klemperer relished molecular spectroscopy and the challenges it offered to improve ways to observe and decipher molecular properties and consequent chemical phenomena. He especially enjoyed applying supersonic beams to chemistry, exclaiming that "they give us a sense of power ... to push molecules around with electric or magnetic fields." His curiosity ranged widely. Early on, he focused on molecules that exist in equilibrium only at high temperatures. Later, his cooling techniques for molecular beams enabled the incisive study of many weakly bound molecular complexes. When Bill became intrigued by spectra of molecules coming from the vast interstellar clouds, he hatched a kinetic scheme involving ionmolecule reactions.

Bill was born on 6 October 1927 in New York City and died peacefully on 5 November 2017 at home in Watertown, Massachusetts. Both of his parents, Paul and Margit, were physicians and raised Bill and his younger brother Martin in New York and New Rochelle. Bill graduated from high school in 1944 and immediately enlisted in the US Navy Air Corps, where he trained as a tail gunner. In 1946 he enrolled in Harvard University, where he majored in chemistry and also met and married Elizabeth Cole, a Radcliffe student. On obtaining his A.B. in 1950, Bill and Beth headed west to the University of California at Berkeley. Mentored by George Pimentel with characteristic gusto, Bill received his $\mathrm{PhD}$ in early 1954.

On a social visit to Harvard, merely intending to see a friendly professor, Bill was offered appointment as an Instructor, which he accepted. That rank, now long gone, was back then considered unlikely to lead to the faculty ladder. However, soon his extraordinary calibre sparkled, as Bill startled both students and faculty with his research. He quickly created a unique spectrometer, ripping items out of conventional gear and adding heavy duty plumbing. By vaporizing solid substances, his apparatus made infrared spectra at high temperatures accessible. The data he obtained on vibrational frequencies for many molecules, especially for oxides and halides, yielded remarkable insights into their chemical bonding.

Before long, Bill began assembling a high-temperature microwave apparatus to attain rotational spectra that would complement the low temperature work carried out in E. Bright Wilson's laboratory, my home as a graduate student. Bill invited me to help. It soon become evident that much better resolution could be attained by molecular beam techniques, such as those being used in Norman Ramsey's physics laboratory across the street. Norman kindly lent us one of his machines during Christmas vacation, 1956, to do some simple experiments. This playful episode impelled both of us to pursue molecular beams for chemistry: Bill for spectroscopy, and I for reaction dynamics.

Bill promptly undertook work to construct a beam apparatus along with Lennard Wharton, a graduate student with an engineering background from MIT. The beam apparatus, dramatically intricate compared with Bill's earlier equipment, took two years in gestation. It and later siblings, enhanced by innovative improvements such as supersonic cooling, produced a cornucopia for molecular spectroscopy, and resulted in unprecedented resolution and chemical scope. Using electric fields to deflect beams and energy levels brought forth many surprising results. Especially important were studies of molecules held together by weak van der Waals forces. Those studies contributed to understanding the specificity and selectivity of such ubiquitous forces in biomolecules. Bill foresaw that myriad pairs of molecules could be weakly linked by simply expanding them together in a supersonic nozzle - a process that offered quantitative access to a wide range of intermolecular forces.

In 1965, Bill was made full professor. His beam experiments had thrived and would do so for more than another three decades. In 1968-1969, Bill took a full year sabbatical. Wanting to study astronomy, he chose to visit Cambridge, England. This sojourn was heavenly for Bill and for Beth and their youngsters, Joyce, Paul and Wendy. Bill both explored the English rose gardens and planted the basic sprouts of his kinetic ion-molecule model. Later, he collaborated with his student Eric Herbst and others in cultivating the kinetic model, and with astrophysicists, especially Pat Thaddeus, who were harvesting dozens of interstellar 'astromolecules', many unexpected.

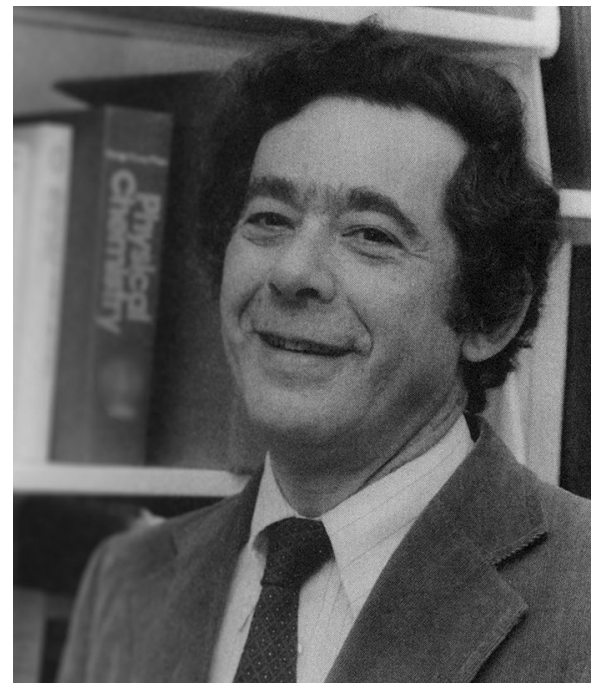

William Klemperer (1927-2017). Credit:

Reproduced with permission from the Annual Review of Physical Chemistry Vol. 46, (c) 1995 Annual Reviews; http://www.annualreviews.org

The huge dark clouds where most interstellar molecules have been seen are 99\% composed of hydrogen and helium. After $\mathrm{H}_{2}$, carbon monoxide is the most abundant molecule, although down by a factor of $10^{-4}$ or more. Ionization by the pervasive flux of $100 \mathrm{MeV}$ cosmic rays creates some $\mathrm{H}_{2}{ }^{+}$and $\mathrm{He}^{+}$, from which emerge many reaction sequences. The $\mathrm{H}_{2}{ }^{+}$ rapidly reacts with $\mathrm{H}_{2}$ to form $\mathrm{H}_{3}{ }^{+}$which, as known from laboratory studies, readily transfers a proton to many other molecular species. Hence Bill predicted that most of the $\mathrm{H}_{3}{ }^{+}$should be converted to $\mathrm{HCO}^{+}$, a very stable species. This prediction was a seminal triumph for Bill's model. Soon after, interstellar emission from a species dubbed Xogen, that had not yet been seen on Earth, was shown to come from the $\mathrm{HCO}^{+}$ion. It turned out to be the most abundant ion in dark clouds and has even been observed in distant galaxies.

The offspring of the $\mathrm{He}^{+}$ions exemplify how chemical kinetics can produce paradoxical results. The extraction by $\mathrm{He}^{+}$of a hydrogen atom from $\mathrm{H}_{2}$ would be very exoergic, yet that reaction does not occur. This is an unusual exception for ion-molecule reactions, but it has been confirmed by laboratory experiments and quantum theory. Instead, 
$\mathrm{He}^{+}$reacts with $\mathrm{CO}$, the second most abundant molecule, to form $\mathrm{C}^{+}$and $\mathrm{O}$. The ionization of helium is thus almost quantitatively transferred to $\mathrm{C}^{+}$, enhancing its concentration a thousand-fold (by the $\mathrm{He} / \mathrm{CO}$ abundance ratio). In turn, $\mathrm{C}^{+}$only feebly reacts with $\mathrm{H}_{2}$, but reacts avidly with methane and acetylene to launch sequences of many organic compounds, including chains punctuated with double and triple bonds. Bill's model explained the paradoxical irony: the mutual distaste of the simplest inorganic species, $\mathrm{He}^{+}$and $\mathrm{H}_{2}$, gives rise to the proliferation of complex organic molecules in the cold interstellar clouds.

Bill Klemperer was a lovable and loving man. Along with his bright, creative intellect, he had good down-to-earth wisdom and humour, and total integrity. He was an earnest citizen, glad to serve on boards and committees for worthy causes. Deservedly, he delighted in his science; in his many intense friendships with students, colleagues and all sorts of people; in his rose garden; and in his joyous family life.

Dudley Herschbach

Department of Chemistry and Chemical Biology, Harvard University, Cambridge,

MA, USA.

e-mail:dherschbach@gmail.com

Published online: 2 January 2018

https://doi.org/10.1038/s41550-017-0365-0 